\title{
Uncontrolled hypertension and orthostatic hypotension in relation to standing balance in elderly hypertensive patients
}

This article was published in the following Dove Press journal:

Clinical Interventions in Aging

28 May 2015

Number of times this article has been viewed

\section{Shanshan Shen' \\ Ting $\mathrm{He}^{\prime}$ \\ Jiaojiao Chu' \\ Jin $\mathrm{He}^{2}$ \\ Xujiao Chen'}

'Department of Geriatrics, Zhejiang Hospital, Hangzhou, ${ }^{2}$ Department of Neurology, Fuyuan Hospital of Yiwu, Jinhua, People's Republic of China
Correspondence: Xujiao Chen Department of Geriatrics, Zhejiang Hospital, No 12, Lingyin Road, Hangzhou 310013 , People's Republic of China $\mathrm{Tel}+86 \quad 8069897567$

Fax+86 57I 87980175

Email lily197459@163.com
Objective: To investigate the associations among uncontrolled hypertension, orthostatic hypotension $(\mathrm{OH})$, and standing balance impairment in the elderly hypertensive patients referred to comprehensive geriatric assessment (CGA).

Methods: In a cross-sectional study, a total of 176 elderly hypertensive patients who underwent CGA were divided into OH group $(n=36)$ and non-OH group $(n=140)$ according to blood pressure measurement in the supine position, after immediate standing up, and after 1 minute and 3 minutes of standing position. Uncontrolled hypertension was defined as blood pressure of $\geq 140 / 90 \mathrm{mmHg}$ if accompanied by diabetes mellitus (DM) or chronic kidney disease (CKD), or $\geq 150 / 90 \mathrm{mmHg}$ if no DM and no CKD. Standing balance, including immediate standing balance and prolonged standing balance, was assessed in side-by-side and tandem stance.

Results: Neither uncontrolled hypertension nor $\mathrm{OH}$ was associated with prolonged standing balance impairment in elderly hypertensive patients $(P>0.05)$. Blood pressure decrease after postural change was significantly associated with immediate standing balance impairment in side-by-side and tandem stance $(P<0.05)$. Patients with $\mathrm{OH}$ were at greater risk of immediate standing balance impairment in both side-by-side and tandem stance than those without $\mathrm{OH}$ (odds ratio [OR] 3.44, 95\% confidence interval [CI] 1.26-9.33, $P<0.05$; OR 3.14, 95\% CI 1.14-8.64, $P<0.01)$. Furthermore, uncontrolled hypertension was associated with immediate standing balance impairment in side-by-side stance (OR 2.96, 95\% CI 1.31-6.68, $P<0.05$ ).

Conclusion: Uncontrolled hypertension, $\mathrm{OH}$, and blood pressure decrease after postural change were associated with immediate standing balance impairment, and therefore, a better understanding of the underlying associations might have major clinical value.

Keywords: hypertension, orthostatic hypotension, balance, elderly

\section{Introduction}

Orthostatic hypotension $(\mathrm{OH})$ is a common clinical phenomenon in the elderly population and has been thought to be an independent risk factor for falls, cardiovascular events, frailty, and mortality. ${ }^{1-6}$ As reported, more than half of the elderly suffer from hypertension, and the prevalence of $\mathrm{OH}$ in this population ranges from $6 \%$ to $30 \% .^{1,7-10}$ Due to aging blood vessels, blood pressure regulation declines with advancing age, and both $\mathrm{OH}$ and hypertension indicate impaired blood pressure regulation. ${ }^{11-13}$ Hypertension itself increases the incidence of $\mathrm{OH},{ }^{14}$ especially uncontrolled hypertension in the elderly patients, who often refuse antihypertensive medication. ${ }^{15-17}$ Compared with participants with controlled hypertension and without $\mathrm{OH}$, those with uncontrolled hypertension and systolic $\mathrm{OH}$ at 1 minute were at greater fall risk. ${ }^{15}$ Moreover, previous studies showed that standing balance impairment may be a predisposing risk factor of falls and increase this risk threefold. ${ }^{18-20}$ The relationship 
between the presence of $\mathrm{OH}$ and reduced ability to maintain standing balance has been recently reported, ${ }^{5,21-24}$ but few studies focus on the association between blood pressure regulation, including uncontrolled hypertension and $\mathrm{OH}$, and standing balance.

It was hypothesized that impaired blood pressure regulation, mainly uncontrolled hypertension and $\mathrm{OH}$, would increase the risk of standing balance impairment, including immediate standing balance and prolonged standing balance impairment. Accordingly, this study assessed the association of uncontrolled hypertension and orthostatic blood pressure change from the supine to standing position with two measurements of standing balance: side-by-side stance and tandem stance.

\section{Methods}

\section{Study design and patients}

This cross-sectional study included 407 elderly hypertension patients who were from the geriatric ward in Zhejiang Hospital for a comprehensive geriatric assessment (CGA) between September 2013 and September 2014. A complete CGA including a general questionnaire, physical, cognitive, and function assessments lasted approximately 1 hour. The CGA was performed by a trained geriatric nurse and a specialized geriatric physician. Approval for the study was granted by Zhejiang Hospital committees and written informed consent was obtained from each study patient.
All participants with hypertension were diagnosed by experienced cardiovascular physicians according to the 2010 Chinese Guidelines for Management of Hypertension. ${ }^{25}$ Hypertension was defined as systolic blood pressure (SBP) of $\geq 140 \mathrm{mmHg}$ and/or diastolic blood pressure (DBP) of $\geq 90 \mathrm{mmHg}$ or currently taking antihypertension medications no matter how high blood pressure was. The inclusion criteria were aged 65 years and older, ability to understand and communicate in Chinese, ability to walk without personal assistance (walking aids permitted), and hearing and vision sufficient for compliance with assessment. Participants with acute infection, malignant tumor, Parkinson's disease, cerebellum diseases, acute cerebrovascular diseases, delirium, terminal illness, severe vision or hearing deficits, or severe cognitive impairment (mini-mental state examination [MMSE] score $\leq 10$ ) were excluded from the study.

A total of 407 potential cases were identified and eventually 353 participants agreed to participate in the study. Of these 353 cases, three patients were not included because of their age; seven patients were excluded due to severe cognitive decline; 13 patients were excluded by reason of acute infection; and 16 patients were repeatedly assessed. Fortyfour patients for whom the data of the orthostatic test were unavailable were excluded, as were 94 other patients due to missing data on standing balance. All the remaining 176 cases were used for analysis. Figure 1 shows the procedure of selecting patients.

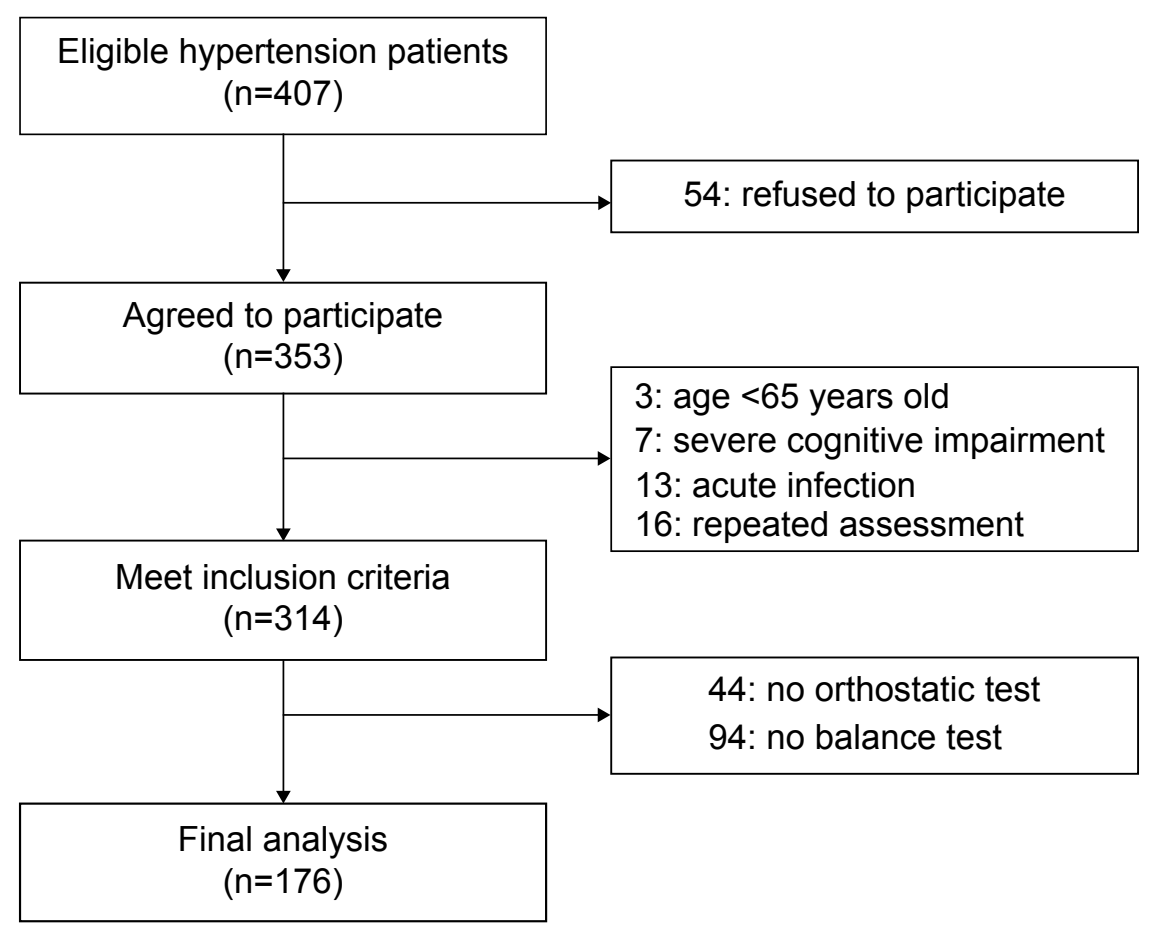

Figure I The procedure of patient selection. 


\section{Data collection}

Socio-demographic data including age, sex, marital status, living arrangement, cigarette smoking, and alcohol use were collected. The body mass index (BMI) was calculated by measuring body weight (kilogram) and body height (meter). Information about concomitant diseases and the usage of medication was recorded by reviewing the hospital medical records. Multiple comorbidities were defined as no less than five kinds of diseases. Patients who took five or more oral prescription drugs were regarded as experiencing polypharmacy. ${ }^{26}$ The MMSE was used to evaluate cognitive functioning. ${ }^{27}$ Depression symptoms were detected by using 15-item geriatric depression scale (GDS-15); a score greater than five indicated the presence of depression symptoms ${ }^{28}$ By using a grip dynamometer, grip strength was measured every 5 minutes when the patients sat straight. The average of the repeated three trials was used for final analysis. Patients walked back and forth once a distance of 4 meters, and the shorter time was recorded to indicate current physical performance. The abilities of balance and gait were similarly considered to assess physical functioning. Venous blood samples were obtained early in the morning from resting fasting patients. Serum 25-hydroxyvitamin D (25-OH D) and serum calcium were tested at the Zhejiang Hospital laboratory.

\section{Standing balance assessment}

The balance subscale of the Tinetti performance-oriented mobility assessment (B-POMA) and the tandem test were used for assessing the ability of standing balance. All patients, wearing nonslip shoes, were asked to walk as briskly as possible with or without walking aids during the assessment. The B-POMA test contained nine static and dynamic tasks for a maximum score of 16 , with a higher score indicating better balance performance; two tasks of B-POMA named immediate standing balance in which the patient was asked to keep side-by-side stance in the first 5 seconds after getting up, and prolonged standing balance reflecting how well to maintain the balance with his/her feet together in the following 10 seconds, were administered. ${ }^{29}$ The patients who had marked staggering, moved feet, marked trunk sway, grabbed object for support or used walker or cane, or mild staggering but manages to stand without grabbing objects, or unable to put feet together, were considered to have standing balance impairment; and otherwise not.

The tandem test was timed in seconds while the patients were keeping their feet in line as still as possible, with the heel of the front foot touching the toes of the rear foot. Cutoff points for the tandem test were selected as 3 seconds and 10 seconds,${ }^{30}$ which were, respectively, defined as immediate standing balance impairment, prolonged standing balance impairment, and stable standing balance. The individuals who were unable to stand with one foot in front of other or start to fall or hold for less than the appointed time were regarded as having standing balance impairment; otherwise, the patients were considered as having stable standing balance. Besides, the participants were asked to recall the history of falls during the past 12 months. Fear of falling, gait problems, and use of any walking aids were self-reported.

\section{$\mathrm{OH}$ measurement}

Supine and standing blood pressure were measured on the left arm by a trained nurse, using an automated sphygmomanometer. SBP and DBP were recorded after at least 5 minutes in the supine position, after immediate standing up, and after 1 minute and 3 minutes of standing position. Either a decline of at least $20 \mathrm{mmHg}$ in SBP and/or at least $10 \mathrm{mmHg}$ in DBP within 3 minutes of standing position in the orthostatic test was considered as $\mathrm{OH} .{ }^{31}$ According to 2014 evidence-based guideline for the management of high blood pressure in adults, ${ }^{32}$ the definition of uncontrolled hypertension was SBP greater than $150 \mathrm{mmHg}$ and/or DBP greater than $90 \mathrm{mmHg}$ in elderly hypertension patients without diabetes mellitus (DM) or chronic kidney disease (CKD), and SBP greater than $140 \mathrm{mmHg}$ and/or DBP greater than $90 \mathrm{mmHg}$ in those with DM or CKD.

\section{Statistical analysis}

The variables were analyzed by using the SPSS 18.0 software (SPSS, Chicago, IL, USA). Conforming to the normal distribution, continuous variables were presented as the mean and standard deviation (SD); conforming to the abnormal distribution, continuous variables were presented as the median and interquartile range (IQR). Categorical variables were presented as a percentage or constituent ratio. The unpaired $t$-test (for normally distributed continuous data), the chi-square test or Fisher's exact test (for categorical data), and the Mann-Whitney $U$-test (for abnormally distributed continuous data) were used to compare the statistical difference between non-OH group and $\mathrm{OH}$ group. Furthermore, by adjustment for confounding factors, the association between standing balance, blood pressure decrease, and uncontrolled hypertension was analyzed using the logistic regression model, which was expressed in odds ratios (ORs) and 95\% confidence intervals (CIs). All significance tests were two-tailed, and statistical significance was assumed as $P<0.05$.

\section{Results \\ Characteristics of patients}

The clinical characteristics of all patients are tabulated in Table 1. The mean SBP and DBP after postural change are 
Table I Comparison of clinical data between the non-OH group and $\mathrm{OH}$ group $(n=176)$

\begin{tabular}{|c|c|c|c|c|}
\hline Characteristics & $\begin{array}{l}\text { All patients } \\
(n=176)\end{array}$ & $\begin{array}{l}\text { Non-OH group } \\
(n=140)\end{array}$ & $\begin{array}{l}\text { OH group } \\
(n=36)\end{array}$ & $P$-value \\
\hline \multicolumn{5}{|l|}{ Socio-demographic characteristics } \\
\hline Age (years), mean $\pm \mathrm{SD}^{\mathrm{b}}$ & $76.7 \pm 6.6$ & $75.9 \pm 6.6$ & $79.6 \pm 5.8$ & 0.003 \\
\hline Men, n (\%) & IOI (57.4) & $81(57.9)$ & $20(55.6)$ & 0.803 \\
\hline Divorced or widowed, n (\%) & $44(25.0)$ & $38(27.1)$ & $6(16.7)$ & 0.195 \\
\hline Current or former smokers, $\mathrm{n}(\%)^{\mathrm{a}}$ & $16(9.1)$ & $14(10.0)$ & $2(5.6)$ & 0.324 \\
\hline Current or former drinkers, $\mathrm{n}(\%)^{\mathrm{a}}$ & $15(8.5)$ & $14(10.0)$ & I (2.8) & 0.145 \\
\hline Living alone, n (\%) & II 5 (7I.4) & $96(72.2)$ & $19(67.9)$ & 0.645 \\
\hline BMI $\left(\mathrm{kg} / \mathrm{m}^{2}\right)$, mean $\pm \mathrm{SD}^{\mathrm{b}}$ & $24.0 \pm 3.1$ & $23.9 \pm 3.0$ & $24.2 \pm 3.5$ & 0.684 \\
\hline \multicolumn{5}{|l|}{ Medical characteristics } \\
\hline \multicolumn{5}{|l|}{ Concomitant medical conditions, $\mathrm{n}(\%)$} \\
\hline Cardiovascular disease & $85(48.3)$ & 7I (50.7) & $14(38.9)$ & 0.205 \\
\hline Cerebrovascular disease & $40(22.7)$ & $27(19.3)$ & $13(36.1)$ & 0.032 \\
\hline Diabetes mellitus & $35(19.9)$ & $28(20.0)$ & $7(19.4)$ & $0.94 I$ \\
\hline Renal disease $^{\mathrm{a}}$ & $22(12.5)$ & $19(13.6)$ & $3(8.3)$ & 0.574 \\
\hline Musculoskeletal disease & $47(26.9)$ & $40(28.6)$ & $7(20.0)$ & 0.306 \\
\hline Comorbidities ( $\geq 5$ diseases), $\mathrm{n}(\%)$ & $80(45.5)$ & $64(45.7)$ & $16(44.4)$ & 0.891 \\
\hline Polypharmacy ( $\geq 5$ drugs), n (\%) & $77(43.8)$ & $59(42.1)$ & $18(50.0)$ & 0.397 \\
\hline GDS ( $\geq 6$ score), $n$ (\%) & $24(13.7)$ & $18(12.9)$ & $6(17.1)$ & 0.583 \\
\hline MMSE, median (IQR) ${ }^{c}$ & $27(24-28)$ & $27(24-28)$ & $27(24-28)$ & 0.926 \\
\hline Gait disorder, n (\%) & $70(39.8)$ & $51(36.4)$ & $19(52.8)$ & 0.074 \\
\hline Fall incidents in previous 12 months, $\mathrm{n}$ (\%) & $45(25.6)$ & $33(23.6)$ & $12(33.3)$ & 0.231 \\
\hline Walking aids, n (\%) & $21(11.9)$ & $14(10.0)$ & $7(19.4)$ & 0.119 \\
\hline Fear of falling, $n(\%)$ & $64(36.4)$ & $51(36.4)$ & $13(36.1)$ & 0.972 \\
\hline Grip strength $(\mathrm{kg})$, mean $\pm S D^{b}$ & $29.5 \pm 9.7$ & $29.9 \pm 9.9$ & $27.9 \pm 9.0$ & 0.267 \\
\hline Four-meter walk (seconds), median (IQR) ${ }^{c}$ & $6.5(5.3-9.1)$ & $6.5(5.3-9.2)$ & $6.0(5.1-7.2)$ & 0.244 \\
\hline \multicolumn{5}{|l|}{ Laboratory data } \\
\hline Calcium (mg/dL), mean $\pm \mathrm{SD}^{\mathrm{b}}$ & $2.3 \pm 0.1$ & $2.3 \pm 0.1$ & $2.2 \pm 0.1$ & 0.367 \\
\hline $25-\mathrm{OH} D(\mathrm{ng} / \mathrm{mL})$, mean $\pm \mathrm{SD}^{\mathrm{b}}$ & $18.3 \pm 9.0$ & $18.4 \pm 9.0$ & $18.0 \pm 9.1$ & 0.844 \\
\hline
\end{tabular}

Notes: All data were analyzed by the chi-square test unless marked. ${ }^{a}$ Fisher's exact test; ${ }^{b}$ the unpaired $t$-test; ' the Mann-Whitney $U$-test.

Abbreviations: $\mathrm{OH}$, orthostatic hypotension; SD, standard deviation; BMI, body mass index; GDS, geriatric depression scale; MMSE, mini-mental state examination; IQR, interquartile range; 25-OH D, 25-hydroxyvitamin D.

summarized in Table 2. The mean age of all patients was 76.7 years $(\mathrm{SD}=6.6$, range 65-91 years), and $101(57.4 \%)$ of them was male. According to the definition of $\mathrm{OH}, 20.5 \%$ patients were diagnosed with $\mathrm{OH}$, and the rest were classified as non-OH.

\section{Comparison of clinical characteristics of non- $\mathrm{OH}$ and $\mathrm{OH}$ groups}

Table 1 shows that the patients in the $\mathrm{OH}$ group were older and with a higher percentage of cerebrovascular disease, mainly cerebral infarction remission without obvious limb disorder, compared with the non-OH group $(P<0.05)$. No significant differences were shown in the comorbidities, polypharmacy, GDS score, MMSE score, and grip strength between the two groups $(P>0.05)$. In terms of fall history, using of walk aids, fear of falling and gait, results showed no statistical differences between the two groups, as well as in the level of calcium and 25-OH D $(P>0.05)$; adjustments for age, sex, osteoarticular diseases, calcium supplement, and vitamin D supplement did not influence the result among the groups regarding the level of serum calcium and 25-OH D.

As for the hypertension duration, stage, and antihypertension therapy, no differences were found between patients with or without $\mathrm{OH}(P>0.05)$. The percentage of uncontrolled hypertension in the $\mathrm{OH}$ group was higher than in the non-OH group $(P<0.01)$. In orthostatic test, compared $\mathrm{OH}$ group with non-OH group, supine SBP was higher, DBP after immediate standing up and standing SBP/DBP after 3 minutes were lower $(P<0.05)$, but there was no significant difference in other assessment time points $(P>0.05)$. Details are presented in Table 2.

\section{Comparison of standing balance function of non- $\mathrm{OH}$ and $\mathrm{OH}$ groups}

Figure 2A shows that the median score of the B-POMA in the $\mathrm{OH}$ group was lower than in the non-OH group (14 vs 15 , $P=0.003)$. In side-by-side stance, $30.6 \%$ of the patients reported impaired immediate standing balance in the $\mathrm{OH}$ group compared to $7.9 \%$ of the patients in the non-OH group 
Table 2 Hypertension correlated characteristics of the non-OH and $\mathrm{OH}$ groups $(n=176)$

\begin{tabular}{|c|c|c|c|c|}
\hline Characteristics & $\begin{array}{l}\text { All patients } \\
(n=\mid 76)\end{array}$ & $\begin{array}{l}\text { Non-OH group } \\
(n=140)\end{array}$ & $\begin{array}{l}\text { OH group } \\
(n=36)\end{array}$ & $P$-value \\
\hline Hypertension duration, n (\%) & & & & 0.984 \\
\hline Unknown & $77(43.8)$ & $61(43.6)$ & $16(44.4)$ & \\
\hline$\leq 10$ years & $51(29.0)$ & $4 \mathrm{I}(29.3)$ & $10(27.8)$ & \\
\hline$>10$ years & $48(27.3)$ & $38(27.1)$ & $10(27.8)$ & \\
\hline Hypertension stage, n (\%) & & & & 0.919 \\
\hline Unknown & $59(33.5)$ & $46(32.9)$ & $13(36.1)$ & \\
\hline Stage I & $16(9.1)$ & $12(8.6)$ & $4(I I . I)$ & \\
\hline Stage 2 & $50(28.4)$ & $41(29.3)$ & $9(25.0)$ & \\
\hline Stage 3 & $51(29.0)$ & $4 \mathrm{I}(29.3)$ & $10(27.8)$ & \\
\hline \multicolumn{5}{|l|}{ Antihypertensive medications, $\mathrm{n}(\%)$} \\
\hline Calcium channel blockers & $100(56.8)$ & $78(55.7)$ & $22(6 I .1)$ & 0.560 \\
\hline AT receptor blockers/ACE inhibitors & $90(5 \mathrm{I} .1)$ & $73(52.1)$ & $17(47.2)$ & 0.598 \\
\hline Diuretics & $36(20.5)$ & $28(20.0)$ & $8(22.2)$ & 0.768 \\
\hline Beta blockers & $35(20.0)$ & $30(21.6)$ & $5(14.3)$ & 0.336 \\
\hline Uncontrolled hypertension, n (\%) & $62(35.2)$ & 39 (27.9) & $23(63.9)$ & $<0.001$ \\
\hline \multicolumn{5}{|c|}{ Blood pressure from supine to stand position $(\mathrm{mmHg})$, mean \pm SD } \\
\hline \multicolumn{5}{|l|}{ SBPb } \\
\hline Supine & $140 \pm 17$ & $138 \pm 16$ & $148 \pm 18$ & 0.001 \\
\hline Immediate & $|33 \pm 2|$ & $133 \pm 20$ & $132 \pm 24$ & 0.826 \\
\hline I minute & $138 \pm 17$ & $139 \pm 16$ & $135 \pm 20$ & 0.341 \\
\hline 3 minutes & $137 \pm 18$ & $138 \pm 17$ & $|29 \pm 2|$ & 0.008 \\
\hline \multicolumn{5}{|l|}{ DBPb } \\
\hline Supine & $72 \pm 10$ & $72 \pm 10$ & $75 \pm 11$ & 0.065 \\
\hline Immediate & $72 \pm 11$ & $73 \pm 11$ & $69 \pm 9$ & 0.036 \\
\hline I minute & $74 \pm 11$ & $74 \pm 10$ & $7 I \pm 11$ & 0.207 \\
\hline 3 minutes & $73 \pm 11$ & $74 \pm 11$ & $66 \pm 9$ & $<0.001$ \\
\hline
\end{tabular}

Notes: All data were analyzed by the chi-square test unless marked. ${ }^{\circ}$ The unpaired $t$-test.

Abbreviations: $\mathrm{OH}$, orthostatic hypotension; AT, angiotensin; ACE, angiotensin-converting enzyme; SD, standard deviation; SBP, systolic blood pressure; DBP, diastolic blood pressure.

$(P<0.01)$. Statistical difference was observed in the percentage of prolonged standing balance impairment between the $\mathrm{OH}$ group and the non-OH group $(61.1 \%$ vs $38.1 \%, P<0.05)$. After adjustment for age, the results remained the same, except for impaired prolonged standing balance (Figure 2B).

In the tandem test, compared with the non-OH group, the percentage of immediate standing balance impairment was respectively higher than prolonged standing balance impairment and stable standing balance in the $\mathrm{OH}$ group ([55.6\% vs $16.7 \%$ vs $27.8 \%$ ] vs [ $25.0 \%$ vs $32.9 \%$ vs $42.1 \%$ ], all $P<0.01$ ), while there was no statistical significance between the latter two parameters $(P>0.05)$. Furthermore, the results were consistent with the above after adjustment for age (Figure 2C), indicating that patients with $\mathrm{OH}$ had standing balance impairment from immediate standing up.

\section{Association of blood pressure measurement with standing balance function}

As shown in Table 3, after adjustment for age, sex, and concomitant cerebrovascular disease, partial correlations analysis found that the B-POMA score was not only associated with SBP decrease at 3 minutes after postural change $(r=-0.180$, $P=0.019$ ), but also negatively related with DBP decrease at 1 minute or 3 minutes after changing the position from supine to standing ( $r=-0.185, P=0.016 ; r=-0.237, P=0.002)$.

Table 4 shows that the decrease in SBP and DBP at 3 minutes after postural change were both associated with impaired immediate standing balance in side-by-side stance adjusted for the same confounders ([OR 3.91, 95\% CI 1.27-12.03]; [OR 3.26, 95\% CI 1.02-9.33]); however, this relationship disappeared between blood pressure decrease and prolonged standing balance impairment among elderly hypertensive patients. In tandem stance, patients with a higher decrease in DBP immediately, or at 1 minute and 3 minutes after postural change were significantly correlated with impaired standing balance ([OR 2.61, 95\% CI 1.01-6.73]; [OR 3.85, 95\% CI 1.33-11.14]; [OR 3.41, 95\% CI 1.25-9.32]), but similar correlations in SBP decrease were not found. Supine blood pressure was not associated with standing balance function in side-by-side stance or tandem stance adjusted for age, sex, and concomitant disease. Patients with $\mathrm{OH}$ were correlated 
A

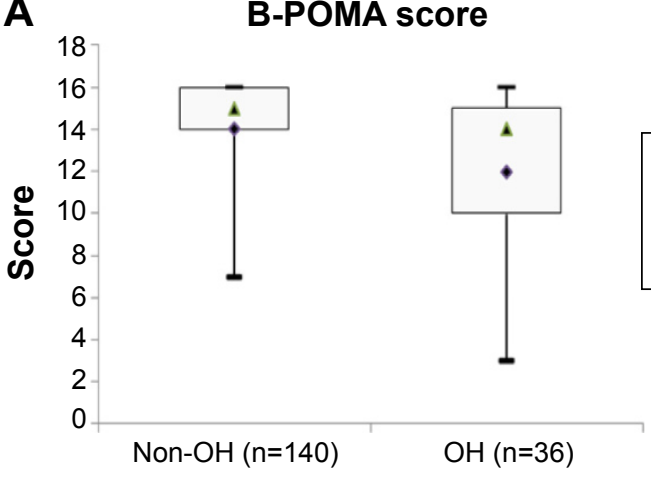

B

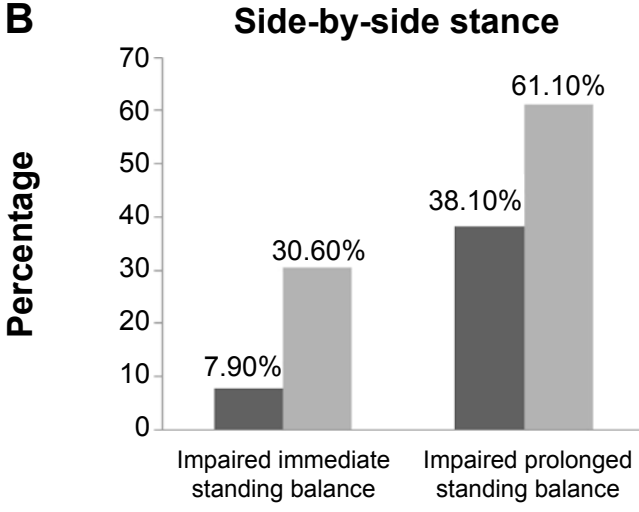

C

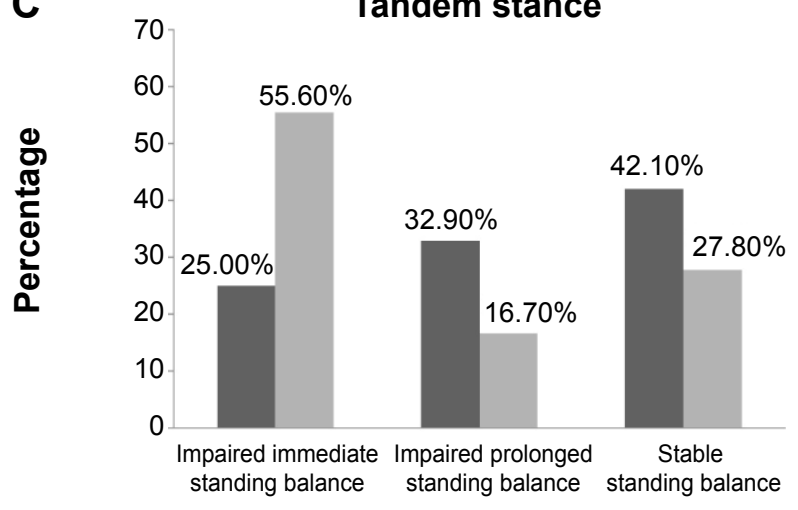

Tandem stance

Figure 2 Comparison of standing balance between non- $\mathrm{OH}$ group and $\mathrm{OH}$ group.

Notes: (A) B-POMA score: the Mann-Whitney $U$-test, $P<0.05$; (B) side-by-side stance: Fisher's exact test, $P<0.0$ I; the chi-square test, $P>0.05$, respectively; (C) the tandem test: the chi-square test, $P<0.01$. All significance tests were adjusted for age.

Abbreviations: B-POMA, the balance subscale of the Tinetti performance-oriented mobility assessment; $\mathrm{OH}$, orthostatic hypotension.

with impaired immediate standing balance in both side-by-side stance and tandem stance ([OR 3.44, 95\% CI 1.26-9.33]; [OR 2.96, 95\% CI 1.31-6.68]). Moreover, compared with controlled hypertension patients, patients with uncontrolled hypertension were more likely to have impairment of immediate standing balance in side-by-side stance (OR 3.14, 95\% CI 1.14-8.64).

\section{Discussion}

This study aimed to explore the association between uncontrolled hypertension, $\mathrm{OH}$, and impaired standing balance in elderly patients with hypertension. Patients with $\mathrm{OH}$ were more likely to have impairment of the ability of immediate standing balance in the positions of side-by-side stance and tandem stance, compared with patients without $\mathrm{OH}$. Blood pressure decrease after postural change was significantly associated with immediate standing balance impairment in the above two positions, similar relationship was found between blood pressure decrease after postural change and B-POMA score. Patients with uncontrolled hypertension were correlated with a higher risk of impairment of immediate standing balance in the side-by-side position than those with controlled hypertension. In addition, no associations were found between serum 25-OH D levels, $\mathrm{OH}$, and standing balance.

\section{Blood pressure decrease, $\mathrm{OH}$, and standing balance}

In previous studies, the close association between $\mathrm{OH}$ and standing balance impairment was found not only in healthy

Table 3 Association between blood pressure decrease and B-POMA score in all elderly patients with hypertension ( $\mathrm{n}=176$ )

\begin{tabular}{|c|c|c|c|c|c|c|}
\hline & \multicolumn{3}{|c|}{ SBP decrease $(\mathrm{mmHg})^{\mathrm{a}}$} & \multicolumn{3}{|c|}{ DBP decrease $(\mathrm{mmHg})^{\mathrm{b}}$} \\
\hline & Immediate & I minute & 3 minutes & Immediate & I minute & 3 minutes \\
\hline B-POMA score & -0.034 & -0.047 & $-0.180^{c}$ & -0.142 & $-0.185^{c}$ & $-0.237^{d}$ \\
\hline
\end{tabular}

Notes: All data were analyzed by partial correlations after adjustment for age, sex, and concomitant cerebrovascular disease. ${ }^{a}$ Supine SBP minus SBP after postural change; bsupine DBP minus DBP after postural change; ${ }^{c} P<0.05$; ${ }^{d} p<0.01$.

Abbreviations: SBP, systolic blood pressure; DBP, diastolic blood pressure; B-POMA, the balance subscale of the Tinetti performance-oriented mobility assessment. 
Table 4 Association between blood pressure decrease and impaired standing balance in all elderly patients with hypertension $(n=176)$

\begin{tabular}{|c|c|c|c|c|c|c|}
\hline & \multicolumn{4}{|c|}{ Side-by-side stance } & \multirow{2}{*}{\multicolumn{2}{|c|}{$\begin{array}{l}\text { Tandem stance } \\
\text { Impaired immediate standing } \\
\text { balance }\end{array}$}} \\
\hline & \multicolumn{2}{|c|}{$\begin{array}{l}\text { Impaired immediate standing } \\
\text { balance }\end{array}$} & \multicolumn{2}{|c|}{$\begin{array}{l}\text { Impaired prolonged standing } \\
\text { balance }\end{array}$} & & \\
\hline & OR $(95 \% \mathrm{Cl})$ & $P$-value & OR $(95 \% \mathrm{Cl})$ & $P$-value & OR $(95 \% \mathrm{Cl})$ & $P$-value \\
\hline \multicolumn{7}{|c|}{ Supine blood pressure ${ }^{a}$} \\
\hline SBP & $1.03(1.00-1.05)$ & 0.086 & $0.99(0.97-1.01)$ & 0.460 & $1.00(0.98-1.03)$ & 0.676 \\
\hline DBP & $1.01(0.96-1.07)$ & 0.621 & $1.00(0.97-1.04)$ & 0.871 & $0.98(0.95-1.02)$ & 0.267 \\
\hline \multicolumn{7}{|c|}{ Blood pressure decrease after postural change } \\
\hline \multicolumn{7}{|c|}{ SBP decrease ${ }^{b}$} \\
\hline Immediate & $1.21(0.36-4.00)$ & 0.760 & $1.06(0.45-2.50)$ & 0.898 & $0.99(0.4 \mathrm{I}-2.40)$ & 0.988 \\
\hline I minute & $0.98(0.18-5.36)$ & 0.977 & $0.42(0.1|-| .6 I)$ & 0.205 & $1.47(0.43-5.05)$ & 0.542 \\
\hline 3 minutes & $3.91(1.27-12.03)$ & 0.017 & $1.54(0.56-4.20)$ & 0.403 & $1.93(0.72-5.16)$ & 0.188 \\
\hline \multicolumn{7}{|l|}{ DBP decrease ${ }^{c}$} \\
\hline Immediate & $2.25(0.70-7.22)$ & 0.172 & $0.86(0.33-2.24)$ & 0.759 & $2.6 \mathrm{I}(1.0 \mathrm{I}-6.73)$ & 0.047 \\
\hline I minute & $2.49(0.74-8.43)$ & 0.143 & $0.94(0.33-2.67)$ & 0.910 & 3.85 (I.33-II.I4) & 0.013 \\
\hline 3 minutes & $3.26(1.02-10.43)$ & 0.047 & $2.32(0.82-6.58)$ & 0.113 & $3.4 \mathrm{I}(1.25-9.32)$ & 0.017 \\
\hline $\mathrm{OH}^{d}$ & 3.44 (1.26-9.33) & 0.016 & $1.73(0.76-3.92)$ & 0.191 & $2.96(1.31-6.68)$ & 0.009 \\
\hline $\begin{array}{l}\text { Uncontrolled } \\
\text { hypertension }\end{array}$ & $3.14(1.14-8.64)$ & 0.027 & $0.93(0.46-1.91)$ & 0.852 & I.82 (0.88-3.76) & 0.108 \\
\hline
\end{tabular}

Notes: All data were from logistic regression analysis with adjustment for age, sex, and concomitant cerebrovascular disease. The ability of standing balance: $0=$ stable, $\mathrm{I}=$ impaired; ${ }^{a}$ measured after at least 5 minutes in the supine position; 'bupine SBP minus SBP after postural change $\geq 20$ mmHg; 'supine DBP minus DBP after postural change $\geq 10 \mathrm{mmHg}$; ${ }^{\mathrm{d}}$ decline of at least $20 \mathrm{mmHg}$ in SBP and/or at least $10 \mathrm{mmHg}$ in DBP within 3 minutes of standing position; eblood pressure of $\geq 140 / 90 \mathrm{mmHg}$ if accompanied with diabetes mellitus (DM) or chronic kidney disease (CKD), or $\geq 150 / 90 \mathrm{mmHg}$ if no DM and no CKD.

Abbreviations: $\mathrm{OR}$, odds ratio; $\mathrm{Cl}$, confidence interval; SBP, systolic blood pressure; DBP, diastolic blood pressure; $\mathrm{OH}$, orthostatic hypotension.

elderly ${ }^{21}$ and older outpatients ${ }^{5}$ but also in the elderly with specific disease, including DM ${ }^{22}$ or Parkinson's disease..$^{23,24}$ In accordance with those studies, we did find this association in elderly hypertensive patients. A cross-sectional cohort study, involving 197 elderly outpatients, indicated that elderly patients with either $\mathrm{OH}$ or greater blood pressure decrease after postural change had an increased risk of reduced ability of maintaining standing balance just in semi-stance with eye closed, but not in side-by-side stance or tandem stance whether eyes of the patients were open or closed. ${ }^{5}$ That is not in line with this study, which showed that both $\mathrm{OH}$ and blood pressure decrease after changing posture were correlated with immediate standing balance impairment in both side-by-side stance (in the first 5 seconds) and tandem stance (in the first 3 seconds), even if measured with the patients' eyes open. The discrepancy in the results may have arisen from the differences in the assessment criteria of standing imbalance and the difference in the characters of study sample.

Upon standing up from the supine position, approximately $500-1,000 \mathrm{~mL}$ blood accumulates in the legs and splanchnic venous vessels, resulting in reduced venous blood return to the heart, and then a transient decline in blood pressure. ${ }^{33}$ In general, this situation can be normally compensated by the arterial baroreceptor reflex..$^{34}$ Once this baroreflex is activated, sympathetic activity will be subsequently enhanced and parasympathetic activity will be lessened, increasing the heart rate and vascular resistance in order to maintain sufficient perfusion of vital organs. ${ }^{35}$ However, as for the patients with $\mathrm{OH}$, these regulation mechanisms might be partly impaired, resulting in a rapid drop in blood pressure after postural change, and as a consequence of failure to timely compensation for recovering and maintaining adequate blood pressure and cerebral perfusion. ${ }^{34,36}$ Moreover, the dynamic cerebral autoregulation plays an important role in maintaining cerebral blood flow (CBF) relatively stable within a few seconds. ${ }^{37-40}$ Therefore, the researchers of some studies regarded the first few seconds of standing as a critical period of cerebral hypoperfusion, ${ }^{41-43}$ which would potentially increase a risk of serious outcomes, such as falls, fall-related injuries, frailty, or even mortality. ${ }^{3,4}$ The hypoperfusion pressure and its consequences might not be manifested in the time following standing, probably because other compensatory mechanisms, such as neurovascular compensation, the skeletal muscle pump, and neurohumoral regulation, are responsible for orthostatic blood redistribution. ${ }^{44}$ Under the circumstances, the body might adapt to the state of hypoperfusion so that it can maintain standing balance in the following time. These results indirectly reflect that the ability of standing balance of the frail body has a time lag in 
the face of the orthostatic change. Based on aforementioned mechanisms, it can be explained why a decline in blood pressure within 5 seconds of posture change was significantly associated with immediate standing balance impairment, but not prolonged standing balance impairment.

\section{Uncontrolled hypertension, $\mathrm{OH}$, and standing balance}

Some clinical studies had shown that compared with controlled hypertension, $\mathrm{OH}$ was more often present in the elderly with uncontrolled hypertension, ${ }^{16}$ while increased blood pressure was negatively associated with the balance impairment in the elderly with hypertension, and that mediated the physical function and the risk of fall. ${ }^{45} \mathrm{~A}$ recent study indicated that the patients with uncontrolled hypertension (blood pressure of $\geq 140 / 90 \mathrm{mmHg}$ ) and systolic $\mathrm{OH}$ at 1 minute were at a greater risk of fall. ${ }^{15}$ Using 2014 evidencebased guidelines for the management of high blood pressure in adults, the results in this study were similar to the above. In this study, elderly hypertensive patients with $\mathrm{OH}$ represented a higher percentage of uncontrolled hypertension, and increased about three times the risk of immediate standing balance. In those uncontrolled hypertensive patients, blood pressure variability, including orthostatic blood pressure variability, is impaired, ${ }^{46}$ leading to decreased $\mathrm{CBF}$, and further causing deep white matter lesions detected by brain magnetic resonance imaging (MRI) ${ }^{47-49}$ Meanwhile, white matter lesions might be associated with standing balance impairment, ${ }^{50,51}$ and probably increased the fall risk. ${ }^{18}$ In addition, another possible explanation is that the levels of basic blood pressure in elderly patients with uncontrolled hypertension were comparatively higher, and the differences in blood pressure after postural change were greater, corresponding increasing the risk of standing balance impairment as a consequence of the combined effect, including blood pressure regulation failure, cerebral autoregulation, neurodegeneration, and deteriorated sensory systems.

\section{Serum 25-OH D, OH, and standing balance}

In the present study, serum 25-OH D levels were not associated with $\mathrm{OH}$ and standing balance impairment, respectively, after adjusting for some potential confounders. Our study was in accordance with the result of another Italian populationbased cohort study which included 2,640 elderly people with a mean age of 74 years. ${ }^{52}$ Nevertheless, previous studies showed that a negative association was observed between serum $25-\mathrm{OH} \mathrm{D}$ levels and $\mathrm{OH}$ in elderly patients. ${ }^{53,54}$
In elderly women with a mean age of 83 years, 25-OH D deficiency was more likely to present in the participants with diastolic $\mathrm{OH},{ }^{55}$ and simultaneously increased the risk of fall. ${ }^{56,57}$ It had been reported that except bone health, 25-OH D deficiency might play a role on the dysfunction of the arterial wall, finally resulting in arterial stiffness and the dysfunction of the baroreflex neural arc with a consequence of short-term maladaptive response to standing up. ${ }^{58-60}$ The discrepancy of the results may attribute to difference in age and the definition of 25-OH D deficiency. Therefore, further studies need large samples in order to focus on different age groups and serum 25-OH D levels to add more clinical value.

\section{Strengths and limitations}

The strength of this present study was a considerable large group of elderly patients with specific diseases who underwent CGA in the geriatric ward. A CGA was done to systematically appraise the function status of the elderly that has not been effectively applied to elderly Chinese patients on a large scale. In addition, this study divided standing balance into two parts, namely, immediate standing balance and prolonged standing balance, measured by side-by-side and tandem positions. Accordingly, additional clinical information about the associations among standing balance, $\mathrm{OH}$, and uncontrolled hypertension was obtained. Moreover, this study also had several limitations. Firstly, blood pressure measurement was confined to 3 minutes after posture change, and therefore delayed $\mathrm{OH}$ that occurs beyond 3 minutes, even 10 minutes or more after standing, ${ }^{61,62}$ may be ignored. Secondly, it is possible that there is a bias about different antihypertensive medications in the elderly with hypertension at a risk of standing balance impairment. The study sample with $\mathrm{OH}$ was too small to detect the possible association. Finally, due to the feature of the cross-sectional study, a causal association among the three variables, namely, standing balance, $\mathrm{OH}$, and uncontrolled hypertension, could not be directly concluded. Further studies with larger sample sizes will be required to investigate the possible causal relationships by longitudinal studies, and add the nonhypertension group for reference in order to make results more comprehensive.

\section{Conclusion}

In conclusion, using CGA, the prevalence of uncontrolled hypertension and standing balance impairment are observed to be higher in elderly hypertensive patients with $\mathrm{OH}$ than in those without $\mathrm{OH}$. The risk of immediate standing balance impairment is approximately three times more in elderly hypertensive patients with $\mathrm{OH}$ or uncontrolled hypertension 
than in those with no $\mathrm{OH}$ or controlled hypertension, but not in prolonged standing balance impairment.

\section{Acknowledgments}

This work was supported by grants from National Health and Family Planning Commission of Scientific Research Fund of People's Republic of China (WKJ2013-2-001) to X Chen and from Science Technology Department of Zhejiang Province (2014C33241) to X Chen.

\section{Disclosure}

The authors report no conflicts of interest in this work.

\section{References}

1. Benvenuto LJ, Krakoff LR. Morbidity and mortality of orthostatic hypotension: implications for management of cardiovascular disease. Am J Hypertens. 2011;24(2):135-144.

2. Fan XH, Wang Y, Sun K, et al. Disorders of orthostatic blood pressure response are associated with cardiovascular disease and target organ damage in hypertensive patients. Am J Hypertens. 2010;23(8):829-837.

3. Romero-Ortuno R, Cogan L, O'Shea D, Lawlor BA, Kenny RA. Orthostatic haemodynamics may be impaired in frailty. Age Ageing. 2011; 40(5):576-583.

4. Xin W, Lin Z, Mi S. Orthostatic hypotension and mortality risk: a meta-analysis of cohort studies. Heart. 2014;100(5):406-413.

5. Pasma JH, Bijlsma AY, Klip JM, et al. Blood pressure associates with standing balance in elderly outpatients. PLoS One. 2014;9(9): e106808.

6. Bae HJ, Lim JH, Cheon SM. Orthostatic hypotension and cognitive impairment in de novo patients with Parkinson's disease. JMov Disord. 2014;7(2):102-104.

7. McDowell A, Engel A, Massey JT, Maurer K. Plan and operation of the Second National Health and Nutrition Examination Survey, 1976-1980. Vital Health Stat 1. 1981;15:1-144.

8. Wolf-Maier K, Cooper RS, Banegas JR, et al. Hypertension prevalence and blood pressure levels in 6 European countries, Canada, and the United States. JAMA. 2003;289(18):2363-2369.

9. Beckett NS, Peters R, Fletcher AE, et al. Treatment of hypertension in patients 80 years of age or older. $N$ Engl J Med. 2008;358(18): 1887-1898.

10. Applegate WB, Davis BR, Black HR, Smith WM, Miller ST, Burlando AJ. Prevalence of postural hypotension at baseline in the Systolic Hypertension in the Elderly Program (SHEP) cohort. J Am Geriatr Soc. 1991; 39(11):1057-1064.

11. Rubio-Ruiz ME, Perez-Torres I, Soto ME, Pastelin G, Guarner-Lans V. Aging in blood vessels. Medicinal agents FOR systemic arterial hypertension in the elderly. Ageing Res Rev. 2014;18C:132-147.

12. Lipsitz LA. Orthostatic hypotension in the elderly. N Engl J Med. 1989; 321(14):952-957.

13. James MA, Potter JF. Orthostatic blood pressure changes and arterial baroreflex sensitivity in elderly subjects. Age Ageing. 1999;28(6): 522-530.

14. Goldstein DS, Pechnik S, Holmes C, Eldadah B, Sharabi Y. Association between supine hypertension and orthostatic hypotension in autonomic failure. Hypertension. 2003;42(2):136-142.

15. Gangavati A, Hajjar I, Quach L, et al. Hypertension, orthostatic hypotension, and the risk of falls in a community-dwelling elderly population: the maintenance of balance, independent living, intellect, and zest in the elderly of Boston study. J Am Geriatr Soc. 2011;59(3):383-389.

16. Lee T, Donegan C, Moore A. Combined hypertension and orthostatic hypotension in older patients: a treatment dilemma for clinicians. Expert Rev Cardiovasc Ther. 2005;3(3):433-440.
17. Fotherby MD, Potter JF. Orthostatic hypotension and anti-hypertensive therapy in the elderly. Postgrad Med J. 1994;70(830):878-881.

18. Muir SW, Berg K, Chesworth B, Klar N, Speechley M. Quantifying the magnitude of risk for balance impairment on falls in communitydwelling older adults: a systematic review and meta-analysis. $J$ Clin Epidemiol. 2010;63(4):389-406.

19. Ganz DA, Bao Y, Shekelle PG, Rubenstein LZ. Will my patient fall? JAMA. 2007;297(1):77-86.

20. Rubenstein LZ. Falls in older people: epidemiology, risk factors and strategies for prevention. Age Ageing. 2006;35(suppl 2):ii37-ii41

21. Overstall PW, Exton-Smith AN, Imms FJ, Johnson AL. Falls in the elderly related to postural imbalance. Br Med J. 1977;1(6056):261-264.

22. Cordeiro RC, Jardim JR, Perracini MR, Ramos LR. Factors associated with functional balance and mobility among elderly diabetic outpatients. Arq Bras Endocrinol Metabol. 2009;53(7):834-843.

23. Hohler AD, Zuzuarregui JR, Katz DI, et al. Differences in motor and cognitive function in patients with Parkinson's disease with and without orthostatic hypotension. Int J Neurosci. 2012;122(5):233-236.

24. Matinolli M, Korpelainen JT, Korpelainen R, Sotaniemi KA, Myllyla VV. Orthostatic hypotension, balance and falls in Parkinson's disease. Mov Disord. 2009;24(5):745-751.

25. Liu LS. Writing Group of Chinese Guidelines for the Management of $\mathrm{H}$. 2010 Chinese guidelines for the management of hypertension. Chin Med J. 2011;39(7):579-615.

26. Viktil KK, Blix HS, Moger TA, Reikvam A. Polypharmacy as commonly defined is an indicator of limited value in the assessment of drug-related problems. Br J Clin Pharmacol. 2007;63(2):187-195.

27. Folstein MF, Folstein SE, McHugh PR. "Mini-mental state". A practical method for grading the cognitive state of patients for the clinician. J Psychiatr Res. 1975;12(3):189-198.

28. Dennis M, Kadri A, Coffey J. Depression in older people in the general hospital: a systematic review of screening instruments. Age Ageing. 2012; 41(2):148-154.

29. Tinetti ME. Performance-oriented assessment of mobility problems in elderly patients. $J$ Am Geriatr Soc. 1986;34(2):119-126.

30. Guralnik JM, Simonsick EM, Ferrucci L, et al. A short physical performance battery assessing lower extremity function: association with self-reported disability and prediction of mortality and nursing home admission. J Gerontol. 1994;49(2):M85-M94.

31. The Consensus Committee of the American Autonomic Society and the American Academy of Neurology. Consensus statement on the definition of orthostatic hypotension, pure autonomic failure, and multiple system atrophy. Neurology. 1996;46(5):1470.

32. Armstrong C. JNC8 Guidelines for the Management of Hypertension in Adults. Am Fam Physician. 2014;90(7):503-504.

33. Mukai S, Lipsitz LA. Orthostatic hypotension. Clin Geriatr Med. 2002; 18(2):253-268.

34. Wieling W, Krediet CT, van Dijk N, Linzer M, Tschakovsky ME. Initial orthostatic hypotension: review of a forgotten condition. Clin Sci. 2007; 112(3): $157-165$.

35. Goldstein DS, Robertson D, Esler M, Straus SE, Eisenhofer G. Dysautonomias: clinical disorders of the autonomic nervous system. Ann Intern Med. 2002;137(9):753-763.

36. Thomas KN, Cotter JD, Galvin SD, Williams MJ, Willie CK, Ainslie PN. Initial orthostatic hypotension is unrelated to orthostatic tolerance in healthy young subjects. J Appl Physiol. 2009;107(2):506-517.

37. TiecksFP,Lam AM, AaslidR, NewellDW.Comparison of static and dynamic cerebral autoregulation measurements. Stroke. 1995;26(6):1014-1019.

38. Kurth CD, Uher B. Cerebral hemoglobin and optical pathlength influence near-infrared spectroscopy measurement of cerebral oxygen saturation. Anesth Analg. 1997;84(6):1297-1305.

39. Hamner JW, Tan CO, Lee K, Cohen MA, Taylor JA. Sympathetic control of the cerebral vasculature in humans. Stroke. 2010;41(1):102-109.

40. Ogoh S, Brothers RM, Eubank WL, Raven PB. Autonomic neural control of the cerebral vasculature: acute hypotension. Stroke. 2008;39(7): 1979-1987. 
41. Immink RV, Secher NH, Roos CM, Pott F, Madsen PL, van Lieshout JJ. The postural reduction in middle cerebral artery blood velocity is not explained by PaCO2. Eur J Appl Physiol. 2006;96(5):609-614.

42. Olufsen MS, Ottesen JT, Tran HT, Ellwein LM, Lipsitz LA, Novak V. Blood pressure and blood flow variation during postural change from sitting to standing: model development and validation. J Appl Physiol. 2005;99(4):1523-1537.

43. Rickards CA, Cohen KD, Bergeron LL, et al. Cerebral blood flow response and its association with symptoms during orthostatic hypotension. Aviat Space Environ Med. 2007;78(7):653-658.

44. Perlmuter LC, Sarda G, Casavant V, Mosnaim AD. A review of the etiology, associated comorbidities, and treatment of orthostatic hypotension. Am J Ther. 2013;20(3):279-291.

45. Hausdorff JM, Herman T, Baltadjieva R, Gurevich T, Giladi N. Balance and gait in older adults with systemic hypertension. Am J Cardiol. 2003; 91(5):643-645.

46. Kario K, Eguchi K, Hoshide S, et al. U-curve relationship between orthostatic blood pressure change and silent cerebrovascular disease in elderly hypertensives: orthostatic hypertension as a new cardiovascular risk factor. J Am Coll Cardiol. 2002;40(1):133-141.

47. Kario K, Pickering TG. Blood pressure variability in elderly patients. Lancet. 2000;355(9215):1645-1646.

48. Godin O, Tzourio C, Maillard P, Mazoyer B, Dufouil C. Antihypertensive treatment and change in blood pressure are associated with the progression of white matter lesion volumes: the Three-City (3C)Dijon Magnetic Resonance Imaging Study. Circulation. 2011;123(3): 266-273.

49. Dufouil C, Chalmers J, Coskun O, et al; PROGRESS MRI Substudy Investigators. Effects of blood pressure lowering on cerebral white matter hyperintensities in patients with stroke: the PROGRESS (Perindopril Protection Against Recurrent Stroke Study) Magnetic Resonance Imaging Substudy. Circulation. 2005;112(11):1644-1650.

50. Tell GS, Lefkowitz DS, Diehr P, Elster AD. Relationship between balance and abnormalities in cerebral magnetic resonance imaging in older adults. Arch Neurol. 1998;55(1):73-79.
51. Starr JM, Leaper SA, Murray AD, et al. Brain white matter lesions detected by magnetic resonance [correction of resonance] imaging are associated with balance and gait speed. J Neurol Neurosurg Psychiatry. 2003; 74(1):94-98.

52. Veronese N, Bolzetta F, De Rui M, et al. Serum 25-hydroxyvitamin D and orthostatic hypotension in old people: the Pro.V.A. study. Hypertension. 2014;64(3):481-486.

53. Soysal P, Yay A, Isik AT. Does vitamin D deficiency increase orthostatic hypotension risk in the elderly patients? Arch Gerontol Geriatr. 2014; 59(1):74-77.

54. McCarroll KG, Robinson DJ, Coughlan A, Healy M, Kenny RA, Cunningham C. Vitamin D and orthostatic hypotension. Age Ageing. 2012; 41(6):810-813.

55. Annweiler C, Schott AM, Rolland Y, Beauchet O. Vitamin D deficiency is associated with orthostatic hypotension in oldest-old women. J Intern Med. 2014;276(3):285-295.

56. Bischoff-Ferrari HA, Dawson-Hughes B, Staehelin HB, et al. Fall prevention with supplemental and active forms of vitamin D: a metaanalysis of randomised controlled trials. BMJ. 2009;339:b3692.

57. Annweiler C, Montero-Odasso M, Schott AM, Berrut G, Fantino B, Beauchet $O$. Fall prevention and vitamin $\mathrm{D}$ in the elderly: an overview of the key role of the non-bone effects. J Neuroeng Rehabil. 2010;7:50.

58. Braam LA, Hoeks AP, Brouns F, Hamulyak K, Gerichhausen MJ, Vermeer C. Beneficial effects of vitamins D and K on the elastic properties of the vessel wall in postmenopausal women: a follow-up study. Thromb Haemost. 2004;91(2):373-380.

59. Kalueff AV, Tuohimaa P. Neurosteroid hormone vitamin D and its utility in clinical nutrition. Curr Opin Clin Nutr Metab Care. 2007;10(1): $12-19$.

60. Annweiler C, Schott AM, Berrut G, et al. Vitamin D and ageing: neurological issues. Neuropsychobiology. 2010;62(3):139-150.

61. Streeten DH, Anderson GH Jr. Delayed orthostatic intolerance. Arch Intern Med. 1992;152(5):1066-1072.

62. Gibbons CH, Freeman R. Delayed orthostatic hypotension: a frequent cause of orthostatic intolerance. Neurology. 2006;67(1):28-32.
Clinical Interventions in Aging

\section{Publish your work in this journal}

Clinical Interventions in Aging is an international, peer-reviewed journal focusing on evidence-based reports on the value or lack thereof of treatments intended to prevent or delay the onset of maladaptive correlates of aging in human beings. This journal is indexed on PubMed Central, MedLine,

\section{Dovepress}

CAS, Scopus and the Elsevier Bibliographic databases. The manuscript management system is completely online and includes a very quick and fair peer-review system, which is all easy to use. Visit http://www.dovepress. com/testimonials.php to read real quotes from published authors. 